\title{
Fund basic research say polled Canadians
}

I $\mathrm{n}$ anticipation of the October federal election, Research Canada released a public opinion poll indicating that funding for health and medical research is on Canadians' minds when it comes to voting.

According to the poll, $84 \%$ of Canadians are more likely to vote for a candidate who supports increased funding for health and medical research. In addition, $92 \%$ of Canadians think the federal government should fund basic research, even if it doesn't deliver quick or commercially applicable results.

Research Canada, which evolved from the Council for Health Research in Canada in 2005, is a national advocacy alliance promoting the benefits of discovery research. Its funding comes from membership fees, and specific support and sponsorships of events.

More than 1000 Canadians over the age of 18 participated in the online survey from Jan. 29 to Feb. 2. Funding for the poll came from seven organizations, including the Association of Faculties of Medicine of Canada and Canada's Research-Based Pharmaceutical Companies (Rx\&D).

Research Canada Chair Ryan Wiley says the current approach to funding isn't balanced. Although the government invests in targeted research that has a defined lifespan and meets the country's strategic, economic and social needs, it doesn't offer enough support for basic research.

Wiley acknowledges that there is a need to push the commercial agenda, "but if we're not filling the pipeline with new knowledge, ideas and discoveries, then we're not going to have much to commercialize down the road, and that is the disconnect."

In the 2015 federal government budget, $\$ 1.5$ billion was allotted to research and development over the next five years. Most of that money will fund research for short-term commercial applications, rather than basic long-term research that may lead to health innovations. For

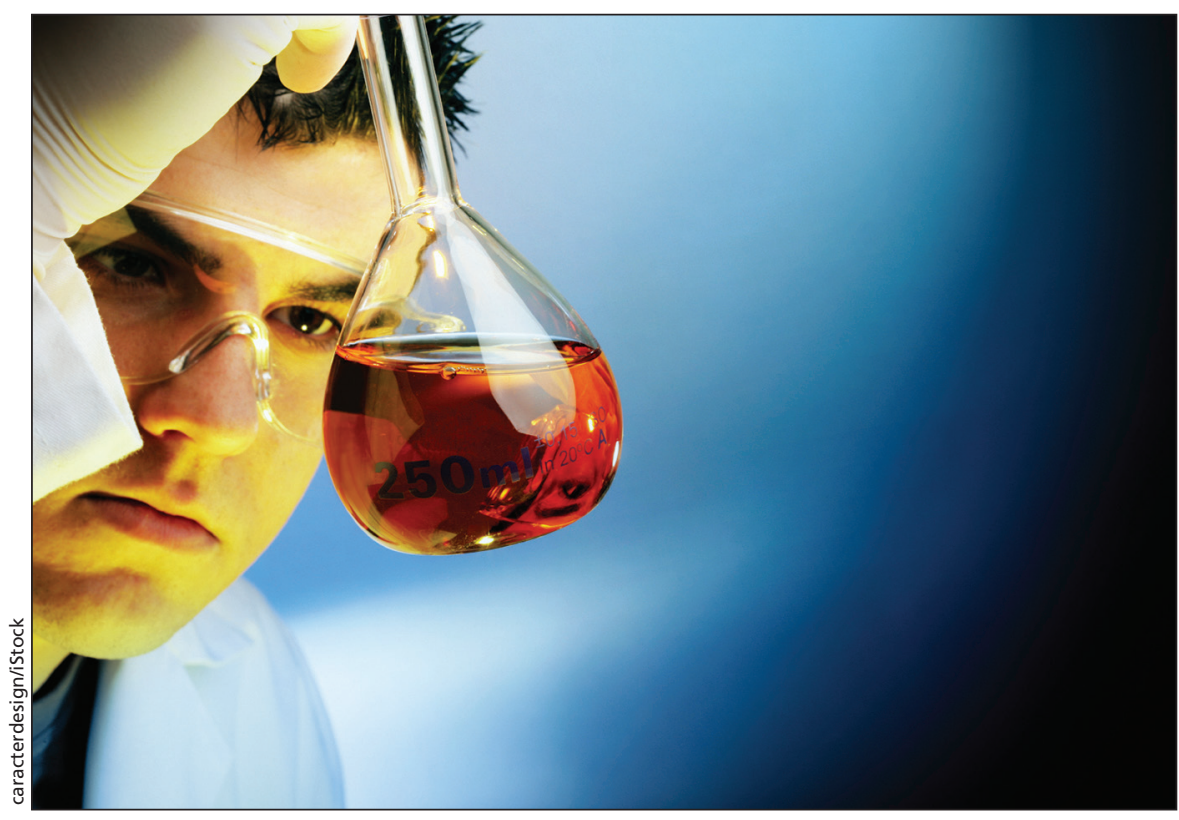

A Research Canada poll finds that $92 \%$ of Canadians think the federal government should fund basic research.

example, the Canadian Institutes of Health Research (CIHR) was given an additional $\$ 15$ million in the recent budget; $\$ 13$ million is being used for its Strategy for Patient-Oriented Research (SPOR), and only \$2 million will go towards basic research.

Bill Tholl, president and CEO of HealthCareCAN, a national advocacy organization for innovative health care and one of the partners in the poll, says this doesn't create a "healthy research ecosystem." There is not enough new money from the budget to support a program like SPOR so it has to take funding for discovery research, he adds.

According to the Research Canada poll, $68 \%$ of Canadians are willing to pay $\$ 1$ more in taxes if the government will invest it toward basic research that leads to health innovation.

In response to the poll's results, CIHR says its funding for programs, including investigator-driven programs, has increased from $\$ 366.7$ million in $2004 / 05$ to $\$ 519.5$ million in $2014 / 15$, and over the next four years it will increase by $\$ 10$ million annually.
But Dr. Geneviève Moineau, president and CEO of the Association of Faculties of Medicine of Canada, one of the poll's sponsors, says this isn't enough because the costs of health research "are increasing at a higher level than the funding is increasing." There are also many indirect costs, such as infrastructure and maintenance, that are borne by faculties of medicine and those costs continue to rise.

As the leaders from the political parties release their election platforms, Research Canada and some of its poll partners say they are looking for specific details on investments in basic healthscience research. If the poll is accurate, most Canadians are on the same page.

"I would say that Canadians do get it," Wiley said. "Clearly we have a Canadian population that knows the importance of investing in basic science ... and based on the results of the poll, they are looking to their candidates to have a similar understanding." - Shannon Lough, CMAJ

CMAJ 2015. DOI:10.1503/cmaj.109-5069 